\title{
CDISC SDTM Cardiovascular Test Name Terminology
}

National Cancer Institute

\section{Source}

National Cancer Institute. CDISC SDTM Cardiovascular Test Name Terminology. NCI

Thesaurus. Code C101846.

Terminology associated with the cardiovascular test name codelist of the Clinical Data

Interchange Standards Consortium (CDISC) Study Data Tabulation Model (SDT M). 